\title{
AgFACT: Linking farmers with facts
}

\author{
G.I. OGLE ${ }^{1}$, A.L. CRAIGIE ${ }^{1}$ and M.J. BAKER ${ }^{2}$ \\ ${ }^{1}$ AgResearch, Ruakura Research Centre, PB 3123, Hamilton \\ ${ }^{2}$ AgResearch, Grasslands Research Centre, PB 11008, Palmerston North
}

\begin{abstract}
The AgLINK bulletin series dominated all agricultural and horticultural information publications from the late 1960s to the late 1980s, when it was discontinued. The collapse of such a high profile series raises questions about the viability of such a mechanism for linking farmers with facts. This failure highlights three key issues: the need to define and allocate the costs based on who benefits; the appropriate positioning of parties within the distribution chain; and a quality specification to which bulletins must adhere. We consider that AgFACT, the AgResearch pastoral agriculture information base which superseded AgLINK in 1997, should largely be cost neutral to science groups in AgResearch. However, the resources for providing information need to be met by science programmes, a cost which is outweighed by the opportunity to communicate with science stakeholders. The costs of distribution and retail need to fall with the other parties who benefit from the dissemination of this information - the retailer and the end user. We also consider that the role of $\mathrm{AgResearch}$ is in manufacture rather than sales to the public, which is best done by the agricultural service sector. AgFACT must maintain tight specifications, to ensure that it is relevant to farmers and other users, accurate and unbiased, and up to date. The penalty for not doing so is a loss of value and, moreover, a risk of it becoming a public liability.
\end{abstract}

Keywords: AgFACT, AgLINK, agricultural information, information base, technology transfer

\section{Introduction}

For 20 years from the late 1960s, the Ministry of Agriculture and Fisheries (MAF) produced a series of information bulletins called AgLINK. Its aim was to provide farmers, horticulturists, advisors, educators and the general public with simple, brief and practical advice - a concept that could be expected to stand the test of time. Initially, a writer was employed to produce one a month, and it was difficult to get scientists involved
(G. Moss pers. comm.). By the mid 1980s this situation had changed dramatically - scientists had provided information for a truly massive 1504 titles, which during the 1970s and early 1980s averaged two AgLINK a week. The topics covered included administration and extension, agricultural science and technology, farm and horticultural production and practice, and more general titles on New Zealand agriculture.

By 1988 the MAF had been divided into a commercialised advisory service and a publicly funded science department, both divisions of MAFTechnology. Neither was willing to continue the AgLINK pamphlet series and, to the bewilderment of the public, the series was decommissioned. But by the mid 1990s public requests for AgLINK were still significant. Three separate investigations undertaken by MAFTechnology had considered the feasibility of re-developing AgLINK but each failed to find suitable solutions (J. Squire pers. comm.). Eventually, AgResearch, formed from the science division of MAFTechnology and DSIR's Grasslands Division, considered that the continuing demand for AgLINK justified developing a successor. In June 1997 this successor was relaunched as AgFACT, a computerised information base. This paper considers the reasons for the fate of $\mathrm{AgLINK}$ and the issues which needed to be overcome in the development of AgFACT.

\section{What were the core issues?}

\section{Who bears the cost?}

AgResearch surveys in 1995 and 1996 highlighted a perception that AgLINK was a free product (Davidson 1995; Ogle 1996). In fact, for a brief period in 1988 consumers were paying $\$ 2.50$ for each pamphlet, often receiving merely a low quality photocopy of the original. The real costs of AgLINK were being absorbed within the funding of MAF. These costs were never clearly defined, but included the costs of administration, printing, writing and distribution. In the late 1980s the funding system for both science and extension activities changed, with an increased emphasis on the "user pays" concept. The outcome was that staff, faced with tight revenue expectations and a more stringent systems of accountability, were no longer able or willing to spend time writing and updating AgLINK. To avoid the risk of liability resulting from the public implementing out 
of date recommendations, AgLINK was decommissioned.

The decision on whether to launch a successor to AgLINK was considered with a great degree of pragmatism. Science businesses invest only where there is a return, or where there are strategic benefits of an equivalent value. At first glance neither appears achievable with an AgLINK successor. However, there is evidence that the Government, the sole shareholder in Crown Research Institutes, wishes to see more tangible relationships between science and the private sector (Upton 1993). AgResearch has justified allocating resources for providing the source information on the basis of the value it offers individual science groups in re-engaging their major stakeholders - Government and farmers. However, the full costs in delivering to the end user are significant and need to be allocated to all parties who benefit from the dissemination of this information.

\section{What role should AgResearch have?}

During the 1980s the Ministry of Agriculture and Fisheries had 200 staff devoted solely to extension and farm advisory activities, with excellent regional coverage. Therefore undertaking the manufacture, distribution and retailing of information bulletins was well within their mandate. AgLINK was produced, reviewed and printed internally then freighted to district offices where the public could call in and pick up any AgLINK in which they were interested. No information is now available on the costs of these activities but it is believed the MAF could not sell an AgLINK at a price capable of recouping even the cost of retailing (F. Philips pers. comm.).

Information technologies are developing rapidly. The technology is available to create, store and deliver information electronically to sites, where hard copies are printed only once the user has made a selection from viewing on a PC. This provides potential savings for updating, reprinting, freight and warehousing.

The issue of retailing costs is more intractable. AgResearch, with nine sites, cannot physically provide the regional coverage that was required to retail AgLINK. Delivery through the Internet currently provides no solutions, as fewer than $5 \%$ of farmers are connected to the Internet. Even with the current expectations that Internet use will grow exponentially, an Internet market would not be viable for at least another two years. Even so, the question of how AgResearch might charge for amounts as small as three dollars over the Internet, without incurring large transaction costs, would remain unresolved. It seems unlikely that AgResearch could be involved with selling AgFACT directly to the public without a viable Internet market. Therefore, with the current state of technology, AgResearch must limit its role to manufacture and distribution.

\section{What is the value of a pamphlet series to retailers?}

Within a distribution chain the role of the retailer to make "sales" is critical. Retailers are unlikely to be interested unless they can see clear benefits to themselves and customers. A smaller business may be able to reduce the point of sale costs, but the primary motivation for selling AgFACT is unlikely to be in making a profit. Retailers need to gain more value than simply that of the AgFACT. This "added value" is anticipated to be the primary motivation for retailing. Through providing AgFACT retailers may gain added value from:

- providing up-to-date advice on topical farming issues;

- reducing the time spent in researching new areas of advice;

- reducing the time taken to write out management advice for clients;

- providing information on non-traditional areas.

\section{Quality standards for AgFACT}

The key to a successful distribution chain is for AgFACT to enhance retailers' profile as "knowledge providers". This denotes key specifications for quality:

- Practical and relevant

- To be of value to farmers

- Accurate and unbiased

- To ensure that the best solutions are recommended

- Up-to-date

- For updating practice recommendations.

Practical and relevant information is not always easy to source, particularly for a science-based company such as AgResearch. The science funding cycle often allows research effort to continue on yesterday's issues. Also, science institutions can inadvertently "hijack" an information system. AgLINK, for example, had difficulty adhering to its original brief of providing "simple, brief and practical advice" for farmers, and was widened to become an internal information service within the Ministry of Agriculture and Fisheries, eventually including such titles as "Secretaries/Role and Position/ An overview" and "Advisory Aids/Microphone Techniques/Preparation and Presentation".

AgFACT titles are currently identified by surveying consultants and company technical representatives about the questions their clients commonly ask of them. This may not accurately identify "relevance", as this can be 
judged only by the end user rather than the consultant. It is therefore imperative that a feedback loop is established early with the end user.

Science is, however, well structured to pursue accuracy, and each AgFACT naturally follows a process of writing, peer review, editing and approval similar to that of scientific publications. AgFACT are written by combining the skills of professional writers and scientists. In general, scientists believe that they should tell the public (including AgResearch stakeholders) about their findings, and journalists believe that they should tell the public about the scientists' findings. Scientists don't trust journalists to do the job properly, journalists think that scientists confuse the public with scientific jargon (Rowarth 1997). For AgFACT writing, the mix seems to work - the scientist retains control of the information and how it is presented, while the journalist reduces the onerous commitment of time and provides the necessary writing skills.

Maintaining AgFACT information presents a greater challenge. In 1997 all 880 of the pastoral AgLINK titles were reviewed for revision and inclusion into the AgFACT catalogue, 65 titles were identified as being relevant today and 30 were sufficiently up to date for rewriting. This attrition represents approximately $8 \%$ of titles becoming out of date in each year. Maintenance is critical to the integrity of the information base. The factor that precipitated the failure of AgLINK was the inability to maintain the 1504-title catalogue, which led to a situation of increasing public liability (F. Philips pers. comm.; J. Squires pers. comm.). Two factors controlling the revision effort are:

- Situations change - New knowledge and technologies often make past advice redundant, particularly if the advice involves cost/benefit analysis or current events;

- Revision requires maintaining partnerships - The constant revision of AgFACT material requires an easy flow of information from the knowledge source. AgResearch knowledge and expertise do not, and never will, cover the full range of issues in pastoral farming, so that these partnerships with other institutions will need to be built up and maintained to establish and maintain a comprehensive information base.

\section{Conclusions}

Experience with AgLINK has been instructive in determining the key issues for the new information series $\mathrm{AgFACT}$. These can be summarised as:

- Nothing is "free" - Anything "free" has a cost to some party who will continually review the value of that investment. In this light AgFACT is developed to be cost neutral to science. Scientists are still expected to provide and control the information, with the cost of their time covered from their science funding. This arrangement is mutually beneficial if AgFACT provides science with an opportunity to transfer information to an important stakeholder.

- AgResearch is a science research company - It manufactures AgFACT, but unless the number of farmer connections on the Internet and mechanisms for charging improve, AgResearch is not well positioned for the role of retailing. The agricultural service sector is better equipped for retailing. This group can gain far more than the face value of the AgFACT by using it as a tool to engage their clientele.

- Big is not necessarily better - AgFACT must be relevant, accurate and easily updated. If the factors determining revision effort are ignored in pursuit of size (i.e., number of titles), maintenance costs will become high. Deferring maintenance will eventually lead to public dissatisfaction, loss of reputation and risk of liability.

\section{REFERENCES}

Davidson, D.M. 1995. Farm management information at your fingertips: a farmer survey February and March 1995. AgResearch Internal Report.

Ogle, G.I. 1996. A telephone survey of information use and requirements of pastoral farmers. AgResearch Internal Report.

Rowarth, Jacqueline 1997. The public understanding and communication of science and technology. Agricultural science 10 (1): 27-28.

Upton, S. 1993. Speech notes for seminar on science funding. Plaza International Hotel, Wellington, NZ, page 11 . 
